\title{
PDL1 expression in inflammatory breast cancer is frequent and predicts for the pathological response to chemotherapy
}

\author{
François Bertucci ${ }^{1,2,3}$, Pascal Finetti ${ }^{1}$, Cécile Colpaert ${ }^{4}$, Emilie Mamessier ${ }^{1}$, Maxime \\ Parizel $^{4}$, Luc Dirix ${ }^{5}$, Patrice Viens ${ }^{1,2,3}$, Daniel Birnbaum ${ }^{1}$, Steven van Laere ${ }^{5}$ \\ ${ }^{1}$ Département d'Oncologie Moléculaire, "Equipe Labellisée Ligue Contre le Cancer", Centre de Recherche en Cancérologie de \\ Marseille (CRCM), Institut Paoli-Calmettes, INSERM UMR1068, CNRS UMR725, Marseille, France \\ ${ }^{2}$ Département d'Oncologie Médicale, CRCM, Institut Paoli-Calmettes, Marseille, France \\ ${ }^{3}$ Faculté de Médecine, Aix-Marseille Université, Marseille, France \\ ${ }^{4}$ Department of Pathology, GZA Hospitals Sint-Augustinus, Antwerp, Belgium \\ ${ }^{5}$ Center for Oncological Research (CORE), Faculty of Medicine and Health Sciences, University of Antwerp, Antwerp Belgium
}

Correspondence to:

François Bertucci, e-mail: bertuccif@ipc.unicancer.fr

Keywords: chemotherapy, inflammatory breast cancer, immune response, PDL1, survival

Received: January 23, $2015 \quad$ Accepted: March 23, $2015 \quad$ Published:April 11, 2015

\section{ABSTRACT}

We retrospectively analyzed PDL1 mRNA expression in 306 breast cancer samples, including 112 samples of an aggressive form, inflammatory breast cancer (IBC). PDL1 expression was heterogeneous, but was higher in IBC than in non-IBC. Compared to normal breast samples, PDL1 was overexpressed in $38 \%$ of IBC. In IBC, PDL1 overexpression was associated with estrogen receptor-negative status, basal and ERBB2-enriched aggressive subtypes, and clinico-biological signs of antitumor T-cell cytotoxic response. PDL1 overexpression was associated with better pathological response to chemotherapy, independently of histo-clinical variables and predictive gene expression signatures. No correlation was found with metastasis-free and overall specific survivals. In conclusion, PDL1 overexpression in IBC correlated with better response to chemotherapy. This seemingly counterintuitive correlation between expression of an immunosuppressive molecule and improved therapeutic response may be resolved if $P D L 1$ expression is viewed as a surrogate marker of a strong antitumor immune response among patients treated with immunogenic chemotherapy. In such patients, PDL1 inhibition could protect activated T-cells or reactivate inhibited $T$-cells and improve the therapeutic response, notably when associated with immunogenic chemotherapy.

\section{INTRODUCTION}

Inflammatory breast cancer (IBC) is an aggressive form of breast cancer with strong metastatic potential $[1,2]$. Nearly $60 \%$ of patients die from metastatic relapse despite a multidisciplinary treatment including anthracycline/taxane-based neo-adjuvant chemotherapy (combined with trastuzumab for ERBB2-positive cases), followed by radical surgery and adjuvant radiotherapy. Pathological complete response (pCR) to neo-adjuvant chemotherapy (obtained in $15-30 \%$ of cases) is a favorable prognostic feature. Adjuvant systemic therapy includes hormone therapy for estrogen receptor (ER)-positive tumors and trastuzumab in case of
ERBB2-positivity [3, 4]. However, the 5-year survival remains inferior to $40 \%$. Even more than in non-IBC, the identification of new therapeutic targets is crucial in IBC, justifying the biological studies published for many decades $[5,6]$ and recently based on highthroughput molecular analyses [7].

The importance of immunity has emerged in breast cancer more recently than in other cancers. Several immune response-related variables have a favorable predictive impact in terms of survival and response to chemotherapy in non-IBC [8-17]. Immune response is a complex phenomenon balanced between activator and inhibitor pathways. Cancer cells can maintain an immunosuppressive microenvironment that favors 
tumor progression. Programmed cell death 1 (PD1) receptor-ligand interaction is a major inhibitor pathway. Programmed death-ligand 1 (PDL1 or CD274), one of the ligands of PD1, is expressed at the surface of many cancer and immune cells such as antigen-presenting cells. Its binding to PD1 suppresses T-cell migration, proliferation and secretion of cytotoxic mediators, and restricts tumor cell killing [18-24]. PDL1 is upregulated in many different cancers and its blocking enhances anticancer immunity. Clinical trials testing anti-PD1 or antiPDL1 drugs have shown promising results with durable responses in different cancers including melanoma, renal, lung, prostate and bladder carcinomas [25-27]. PDL1 expression by tumor and/or infiltrating immune cells has been shown to correlate with a therapeutic response $[25$, 26, 28-30].

PDL1 expression has been studied in different cancers [31-42], with evidence of histo-clinical correlations in several studies. A few studies have been reported in non-IBC [43-51], but never in IBC. Here, we have retrospectively analyzed $P D L 1$ mRNA expression in 112 IBC profiled using DNA microarrays to determine its prevalence and to search for correlations with histoclinical features, including response to chemotherapy and survival.

\section{RESULTS}

\section{$P D L 1$ expression is higher in $I B C$ than non-IBC}

We analyzed $P D L 1$ expression in clinical samples of 112 IBC and 194 non-IBC collected within the World IBC Consortium. Their clinical characteristics are shown in Table 1. IBC patients were younger than non-IBC patients, and IBC samples showed more often than nonIBC samples poor-prognosis features $(p<0.01$; Fisher's exact test): AJCC stage 3-4, ductal type, high grade, ERnegative, PR-negative and ERBB2-positive status, and aggressive molecular subtypes (basal, ERBB2-enriched). The 5-year metastasis-free survival (MFS) was 49\% (95\%CI: $37-64 \%)$ in IBC patients and $82 \%(95 \% \mathrm{CI}$ : $76-88 \%)$ in non-IBC patients ( $p=2.7 \mathrm{E}-9$; log-rank test). Such expected differences confirmed the coherence of our data set.

$P D L 1$ expression level was heterogeneous across IBC samples with a range of intensities over 3 decades in $\log _{2}$ scale (Figure 1A). A similar range of expression was observed in non-IBC samples, but expression was higher in IBC than non-IBC samples ( $p=0.02$, Student's $t$-test; Figure 1B). As compared to normal breast (NB) samples, $38 \%$ of IBC samples (42 out of 112) showed $P D L 1$ overexpression (ratio $\mathrm{T} / \mathrm{NB} \geq 2$; hereafter defined as "PDL1-high" group) and 62\% (70 out of 112) did not show overexpression (ratio <2; "PDL1-low" group). For comparison, $28 \%$ of non-IBC samples showed PDL1 overexpression.

\section{Correlations of $P D L 1$ expression with histo- clinical characteristics in IBC}

We searched for correlations between PDL1 expression status (high- versus low- groups) and histoclinical variables in IBC samples (Table 2). No correlation was found with patients' age, AJCC stage, histological type and grade, PR and ERBB2 status. By contrast, PDL1 expression correlated with the ER status and the molecular subtype of samples (Fisher's exact test). Tumors in the "PDL1-high" group were more frequently ER-negative than tumors in the "PDL1-low" group (57\% vs 34\%, $p$ $=0.029$ ). The percentages of ERBB2-enriched subtypes and basal subtypes were higher in the "PDL1-high" group than "PDL1-low" group (36 vs 19\%, and $33 v s$ $20 \%$, respectively), whereas the percentages of luminal A subtypes and luminal B subtypes were lower (10 vs 24\%, and $10 v s 26 \%$, respectively).

\section{Correlations of $P D L 1$ expression with immune parameters}

Given the role of PDL1 in immunity, we searched for correlations (Fisher's exact test) between PDL1 expression and immunity-related factors in IBC samples (Table 3). First, we found a correlation with the lymphocyte infiltrate (both peri-tumoral and intratumoral tumor-infiltrative lymphocytes, TILs), available for 44 samples and scored in four categories (none, small, moderate, or strong infiltrate): the percentage of "PDL1high" samples increased with the degree of lymphocyte infiltrate $(p=0.001)$. Second, PDL1 expression was associated with T-cell-specific, CD8+ T-cell-specific and B-cell-specific gene expression signatures [52]: the percentage of samples with higher expression of these signatures was higher in the "PDL1-high" group $(p<$ $0.01)$. Third, $P D L 1$ expression was associated $(p<0.0001)$ with two gene expression signatures (LCK metagene [10] and 28-kinase metagene [11]) reflecting the immune response and in particular cytotoxic T-cell response. Finally, the probability of activation [53] of IFN $\alpha$, IFN $\gamma$, and TNF $\alpha$ pathways was higher in the "PDL1-high" group $(p<0.00001$; Fisher's exact test). Altogether, these results suggested that $P D L 1$ expression in IBC is associated with anti-tumor T-cell response.

\section{Biological processes associated with $P D L 1$ overexpression in IBC}

Supervised analysis identified 1, 774 genes differentially expressed between the "PDL1-high" group $(N=42)$ and the "PDL1-low" group $(N=70)$, including 1, 607 genes overexpressed and 167 genes underexpressed in the "PDL1-high" group (Supplementary Table 1). Ontology analysis of the 1, 607 genes overexpressed (Supplementary Table 2) revealed 
Table 1: Histo-clinical characteristics of IBC and non-IBC samples

\begin{tabular}{|c|c|c|c|c|}
\hline Characteristics $^{*}$ & $N$ & $\operatorname{IBC}(N=112)$ & non-IBC $(N=194)$ & $P . v a l u e$ \\
\hline Age, years & & & & $6.67 E-03$ \\
\hline$<=50$ & 115 & $53(48 \%)$ & $62(32 \%)$ & \\
\hline$>50$ & 189 & $57(52 \%)$ & $132(68 \%)$ & \\
\hline AJCC stage & & & & $3.35 \mathrm{E}-55$ \\
\hline 1 & 65 & $0(0 \%)$ & $65(34 \%)$ & \\
\hline 2 & 97 & $0(0 \%)$ & $97(51 \%)$ & \\
\hline 3 & 106 & $85(76 \%)$ & $21(11 \%)$ & \\
\hline 4 & 34 & $27(24 \%)$ & $7(4 \%)$ & \\
\hline Histological type & & & & $9.23 \mathrm{E}-04$ \\
\hline Ductal & 250 & $101(92 \%)$ & $149(77 \%)$ & \\
\hline Other & 54 & $9(8 \%)$ & $45(23 \%)$ & \\
\hline Histological grade & & & & $3.76 \mathrm{E}-16$ \\
\hline 1 & 50 & $0(0 \%)$ & $50(26 \%)$ & \\
\hline 2 & 108 & $27(25 \%)$ & $81(42 \%)$ & \\
\hline 3 & 140 & $79(75 \%)$ & $61(32 \%)$ & \\
\hline ER status & & & & $2.12 \mathrm{E}-03$ \\
\hline Negative & 97 & $48(43 \%)$ & $49(25 \%)$ & \\
\hline Positive & 209 & $64(57 \%)$ & $145(75 \%)$ & \\
\hline PR status & & & & $6.58 \mathrm{E}-05$ \\
\hline Negative & 106 & $55(49 \%)$ & $51(26 \%)$ & \\
\hline Positive & 200 & $57(51 \%)$ & $143(74 \%)$ & \\
\hline ERBB2 status & & & & $4.88 \mathrm{E}-04$ \\
\hline Negative & 248 & $79(71 \%)$ & $169(87 \%)$ & \\
\hline Positive & 58 & $33(29 \%)$ & $25(13 \%)$ & \\
\hline Molecular subtypes & & & & $1.00 \mathrm{E}-06$ \\
\hline Basal & 57 & $28(25 \%)$ & $29(15 \%)$ & \\
\hline ERBB2-enriched & 47 & $28(25 \%)$ & $19(10 \%)$ & \\
\hline Luminal A & 115 & $21(19 \%)$ & $94(48 \%)$ & \\
\hline Luminal B & 62 & $22(20 \%)$ & $40(21 \%)$ & \\
\hline Normal-like & 25 & $13(12 \%)$ & $12(6 \%)$ & \\
\hline 5-year MFS ${ }^{* *}$ & 269 & $49 \%$ (CI95 37-64) & $82 \%($ CI95 76-88) & $2.66 \mathrm{E}-09$ \\
\hline Follow-up, median (months) & 269 & 43 & 75 & \\
\hline
\end{tabular}

*data were missing for some characteristics: age and histological type for 2 cases $(<1 \%)$, AJCC stage for $4(<1.5 \%)$, and histological grade for $8(2.6 \%)$

**assessed in the non-stage 4 cases and missed for 1 case

a major involvement in the regulation of local immune response, notably the activation of T-cells. Many genes coded for proteins related to T-cell receptor signaling (e.g. TCR alpha, beta, delta, CD2, CD3D, CD3E, CD8A, CD247, KLRK1), T-cells differentiation (e.g. CD27, EOMES, STAT1, STAT4), T-cells activation (e.g. ITK, $J A K 3, L C K, Z A P 70$ ), cytotoxic effector molecules (e.g.
GZMA/B/H/K, ClQA/B, GNLY, PRF1), inflammation/ anti-tumor cytokines (e.g. IL2RA, IL2RB, IL2RG, IL12RB1, IL12RB2, IL15, IL15RA, IL18BP, IL18, IL21R, $I L 27 R A$, interferon gamma (IFNG) and its receptor, as well as many interferon-induced proteins, $T N F, L T B$ ), and chemokines related to T-cells activation and homing (e.g. $C C L 2 / 4 / 5 / 8 / 18, C X C L 1, C X C L 9 / 10 / 11$, chemokine 

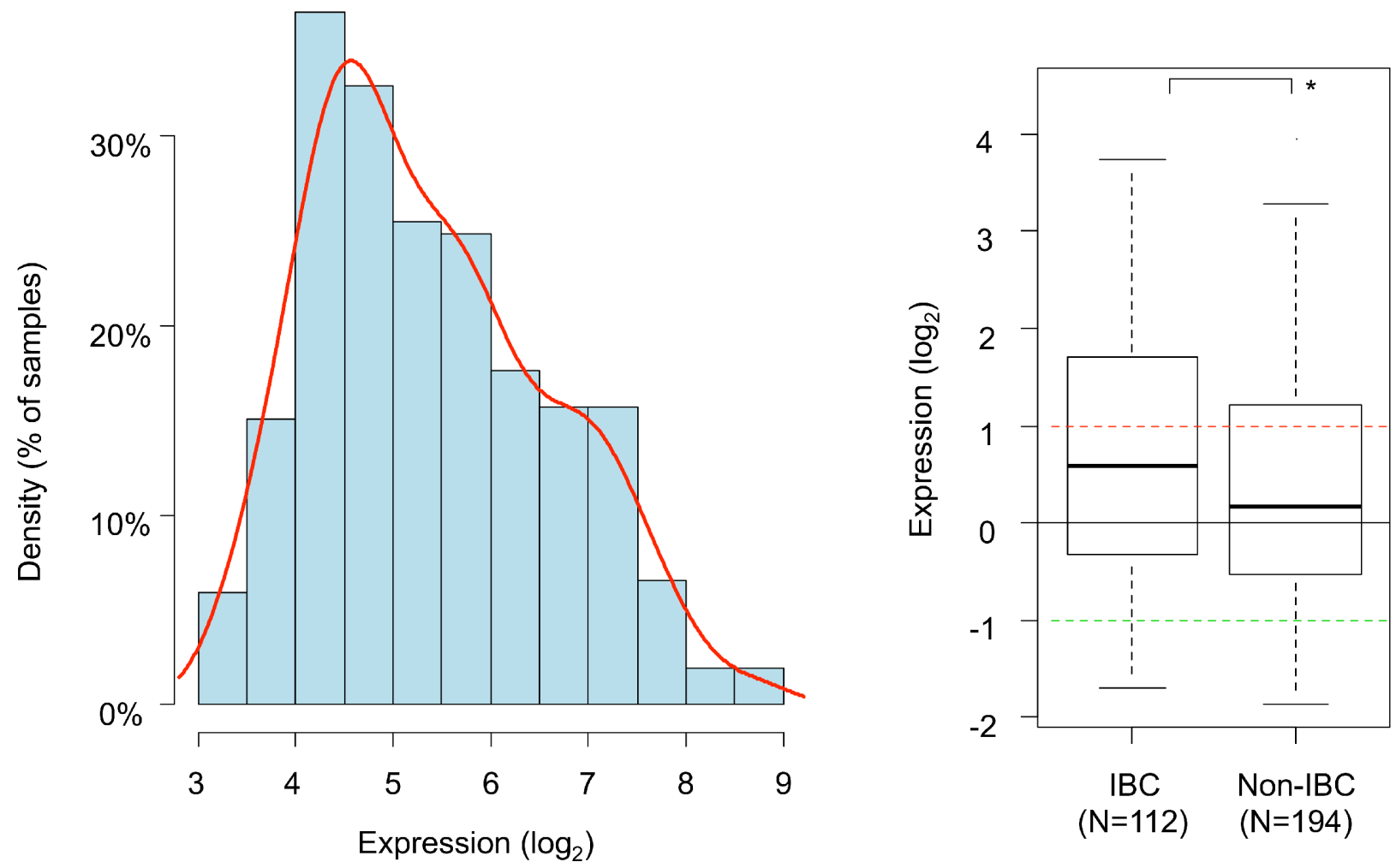

Figure 1: PDL1 mRNA expression across clinical IBC and non-IBC samples. A. Histogram of distribution of $P D L 1$ expression levels $\left(\log _{2}\right)$ across the 112 IBC samples ( $\log _{2}$ scale) after normalization. The red line represents the density curve of distribution. B. PDL1 expression level $\left(\log _{2}\right)$ reported as a box plot according to the type of samples: IBC and non-IBC. The black horizontal line represents the expression level in normal breast samples, the red and green lines represent the thresholds for "PDL1-high" and "PDL1-low" groups respectively. The $p$-value is indicated (Student's $t$-test) are indicated as follows: ${ }^{*}, p<0.05$.

(C-C or C-X-C motifs) receptors). In addition, several overexpressed genes were MHC-related molecules, involved in the processing of endogenous antigens and presentation to cytotoxic and helper T-cells: HLA-I or HLA-I-related molecules (e.g. $H L A-A / B / C / E / F / G$, butyrophilin family members), but also HLA-II molecules (e.g. $H L A-D M / D O / D P / D Q / D R, C D 74$ ), and molecules involved in the degradation of cytosolic peptides across the endoplasmic reticulum into the membrane-bound compartment where class I molecules assemble (e.g. $T A P 1, T A P B P$, many proteasome subunits). Interestingly, CTLA4 and LAG3, which code for markers of T-cells exhaustion, were strongly overexpressed in the "PDL1high" group. HAVCR2 (TIM3), another marker of T-cells exhaustion, was also upregulated in the "PDL1-high" group, whereas PD1 or BTLA molecules were not. PRDM1 (also known as BLIMP1); IDO and TGFB1, which code for cytokines synthesized in exhausted T-cells, were overexpressed in this group as well. Genes overexpressed in the "PDL1-low" group were involved in the response to hormone stimuli.

\section{PDL1 expression correlates with pathological response to chemotherapy in IBC}

The pathological response to neo-adjuvant anthracycline-based chemotherapy was documented for 66 out of 112 patients with IBC, of which $22(33 \%)$ had achieved pCR (pCR group) and 44 (67\%) had not (no-pCR group). Univariate analysis for $\mathrm{pCR}$ prediction (logit link test; Table 4) showed that PDL1 expression was associated with pCR: the pCR rate was 50\% in the "PDL1-high" group versus $22 \%$ in the "PDL1-low" groups $(p=0.03)$ with an OR for pCR equal to 3.4 (95\%CI 1.04-11.51). By contrast, patients' age, histological type and grade, ER, progesterone receptor (PR) and ERBB2 status, and molecular subtypes were not, with a trend for better response in PR-negative versus PR-positive tumors $(p=0.059)$. Regarding the two signatures reported as predictive for pathological response in non-IBC, the $\mathrm{FAC} / \mathrm{T}$ response signature was associated with pathological response in our IBC series $(p=0.046)$ and the Stromal signature tended to be associated $(p=0.052)$. In multivariate analysis incorporating the four variables with a 
Table 2: Correlations of $P D L 1$ expression with histo-clinical characteristics in IBC

\begin{tabular}{|c|c|c|c|c|}
\hline \multirow[t]{2}{*}{ Characteristics $^{*}$} & \multirow[t]{2}{*}{$N$} & \multicolumn{2}{|c|}{ IBC } & \multirow[t]{2}{*}{$P$.value } \\
\hline & & $\overline{\text { PDL1-low }}$ & PDL1-high & \\
\hline Age, years & & & & 0.693 \\
\hline$<=50$ & 53 & $35(50 \%)$ & $18(45 \%)$ & \\
\hline$>50$ & 57 & $35(50 \%)$ & $22(55 \%)$ & \\
\hline AJCC stage & & & & 0.37 \\
\hline 3 & 85 & $51(73 \%)$ & $34(81 \%)$ & \\
\hline 4 & 27 & $19(27 \%)$ & $8(19 \%)$ & \\
\hline Histological type & & & & 0.151 \\
\hline Ductal & 101 & $62(89 \%)$ & $39(98 \%)$ & \\
\hline Other & 9 & $8(11 \%)$ & $1(2 \%)$ & \\
\hline Histological grade & & & & 0.248 \\
\hline 1 & 0 & $0(0 \%)$ & $0(0 \%)$ & \\
\hline 2 & 27 & $20(30 \%)$ & $7(18 \%)$ & \\
\hline 3 & 79 & $47(70 \%)$ & $32(82 \%)$ & \\
\hline ER status & & & & $2.94 \mathrm{E}-02$ \\
\hline Negative & 48 & $24(34 \%)$ & $24(57 \%)$ & \\
\hline Positive & 64 & $46(66 \%)$ & $18(43 \%)$ & \\
\hline PR status & & & & 0.436 \\
\hline Negative & 55 & $32(46 \%)$ & $23(55 \%)$ & \\
\hline Positive & 57 & $38(54 \%)$ & $19(45 \%)$ & \\
\hline ERBB2 status & & & & 0.67 \\
\hline Negative & 79 & $48(69 \%)$ & $31(74 \%)$ & \\
\hline Positive & 33 & $22(31 \%)$ & $11(26 \%)$ & \\
\hline Molecular subtypes & & & & $2.01 \mathrm{E}-02$ \\
\hline Basal & 28 & $14(20 \%)$ & $14(33 \%)$ & \\
\hline ERBB2-enriched & 28 & $13(19 \%)$ & $15(36 \%)$ & \\
\hline Luminal A & 21 & $17(24 \%)$ & $4(10 \%)$ & \\
\hline Luminal B & 22 & $18(26 \%)$ & $4(10 \%)$ & \\
\hline Normal-like & 13 & $8(11 \%)$ & $5(12 \%)$ & \\
\hline
\end{tabular}

*data were missing for some characteristics: age and histological type for 2 cases $(<2 \%)$, and histological grade for $6(5 \%)$

$p$-value inferior to 0.10 in univariate analysis (PDL1 group, PR status, and the two signatures), only the PDL1 group remained significant $(p=0.046)$, suggesting independent predictive value (Table 4).

\section{Correlations of $P D L 1$ expression with survival in IBC}

We first assessed the prognostic value of $P D L 1$ expression in term of MFS, which was annotated for 85 patients with stage 3 IBC: 46 remained metastasis-free during a median follow-up of 43 months (median MFS: 59 months) and 39 displayed metastatic relapse. The 5-year MFS rate was 49\% (95\%CI: 37-64\%) (Figure 2A). In univariate analysis, $P D L 1$ expression was not associated with MFS ( $p=0.479$, log-rank test; Figure 2B), whereas ERBB2 status was $(p=0.046)$ and ER status tended to be associated with MFS ( $p=0.075$; Supplementary Table 3$)$.

The results were similar with respect to overall specific survival (OSS) for the 85 patients, including 49 who remained alive during a median follow-up of 53 months (median OSS: 78 months) and 36 who died from disease progression. The 5 -year OSS was $63 \%(95 \% \mathrm{CI}$ : $52-76 \%$ ) (Figure 2A). PDL1 expression was not associated 
Table 3: Correlations of $P D L 1$ expression with immune-related parameters in IBC

\begin{tabular}{|c|c|c|c|c|}
\hline \multirow[t]{2}{*}{ Characteristics } & \multirow[t]{2}{*}{$N$} & \multicolumn{2}{|c|}{ IBC } & \multirow[t]{2}{*}{$P$. value } \\
\hline & & "PDL1-low" & "PDL1-high" & \\
\hline Lymphocyte infiltrate & & & & $1.54 \mathrm{E}-03$ \\
\hline 0 & 9 & $8(33 \%)$ & $1(5 \%)$ & \\
\hline 1 & 13 & $9(38 \%)$ & $4(20 \%)$ & \\
\hline 2 & 11 & $6(25 \%)$ & $5(25 \%)$ & \\
\hline 3 & 11 & $1(4 \%)$ & $10(50 \%)$ & \\
\hline T-cell metagene & & & & $1.16 \mathrm{E}-04$ \\
\hline High & 43 & $17(24 \%)$ & $26(62 \%)$ & \\
\hline Low & 69 & $53(76 \%)$ & $16(38 \%)$ & \\
\hline CD8+ T-cell metagene & & & & $1.09 \mathrm{E}-02$ \\
\hline High & 34 & $15(21 \%)$ & $19(45 \%)$ & \\
\hline Low & 78 & $55(79 \%)$ & $23(55 \%)$ & \\
\hline B-cell metagene & & & & $2.74 \mathrm{E}-06$ \\
\hline High & 45 & $16(23 \%)$ & $29(69 \%)$ & \\
\hline Low & 67 & $54(77 \%)$ & $13(31 \%)$ & \\
\hline LCK metagene & & & & $5.11 \mathrm{E}-05$ \\
\hline High & 35 & $12(17 \%)$ & $23(55 \%)$ & \\
\hline Low & 77 & $58(83 \%)$ & $19(45 \%)$ & \\
\hline 28-kinase metagene & & & & $2.96 \mathrm{E}-06$ \\
\hline High & 22 & $4(6 \%)$ & $18(43 \%)$ & \\
\hline Low & 90 & $66(94 \%)$ & $24(57 \%)$ & \\
\hline IFN $\alpha$ biological pathway & & & & $6.06 E-06$ \\
\hline Not activated & 52 & $44(63 \%)$ & $8(19 \%)$ & \\
\hline Activated & 60 & $26(37 \%)$ & $34(81 \%)$ & \\
\hline IFN $\gamma$ biological pathway & & & & $4.34 \mathrm{E}-09$ \\
\hline Not activated & 53 & $48(69 \%)$ & $5(12 \%)$ & \\
\hline Activated & 59 & $22(31 \%)$ & $37(88 \%)$ & \\
\hline TNF $\alpha$ biological pathway & & & & $4.64 \mathrm{E}-09$ \\
\hline Not activated & 56 & $50(71 \%)$ & $6(14 \%)$ & \\
\hline Activated & 56 & $20(29 \%)$ & $36(86 \%)$ & \\
\hline
\end{tabular}

with OSS in our IBC series $(p=0.852$, log-rank test; Figure $2 \mathrm{~B})$, whereas ERBB2 status was $(p=0.010)$ and ER and PR statutes tended to be associated with OSS ( $p=0.057$ and $p=0.053$ respectively; Supplementary Table 3 ).

\section{DISCUSSION}

IBC in an aggressive form of breast cancer that could benefit from innovating therapeutic strategies. Given the promising results of PDL1 inhibitors in different cancers, we aimed at documenting the expression of $P D L 1$ in a series of clinical IBC samples and to search for histo-clinical correlations. PDL1 overexpression was found in more than one third of samples and correlated with aggressive molecular subtypes (basal and ERBB2-enriched) and better pathological response to chemotherapy.

So far, PDL1 expression in cancers has been essentially studied at the protein level using IHC. Here, we based our analysis on mRNA expression measured using DNA microarrays for several reasons. First, PDL1 IHC is not yet standardized and many discordant results have been reported across studies, notably in prognostic studies [54]. Several antibodies are available but lack specificity 
Table 4: Univariate and multivariate analysis for pathological response to neo-adjuvant chemotherapy in IBC

\begin{tabular}{|c|c|c|c|c|c|c|}
\hline \multirow[t]{2}{*}{ Characteristics } & \multicolumn{3}{|c|}{ Univariate analysis } & \multicolumn{3}{|c|}{ Multivariate analysis } \\
\hline & $N$ & OR [CI95] & $p$-value & $N$ & OR [CI95] & $p$-value \\
\hline Age, years $>50$ vs. $<=50$ & 64 & $0.72[0.29-1.72]$ & 0.533 & & & \\
\hline Histological type, other vs. ductal & 64 & $0.38[0.04-1.94]$ & 0.392 & & & \\
\hline Histological grade, 3 vs. 2 & 60 & $1.11[0.42-3.05]$ & 0.859 & & & \\
\hline ER status, positive vs. negative & 66 & $0.58[0.24-1.37]$ & 0.296 & & & \\
\hline PR status, positive vs. negative & 66 & $0.36[0.14-0.86]$ & 0.059 & 66 & $0.49[0.17-1.38]$ & 0.258 \\
\hline $\begin{array}{l}\text { ERBB2 status, positive vs. } \\
\text { negative }\end{array}$ & 66 & $0.48[0.15-1.3]$ & 0.247 & & & \\
\hline $\begin{array}{l}\text { Molecular subtypes, ERBB2- } \\
\text { enriched vs. basal }\end{array}$ & 66 & $0.95[0.28-3.18]$ & 0.947 & & & \\
\hline Luminal A vs. basal & 66 & $0.24[0.05-0.94]$ & 0.110 & & & \\
\hline Luminal B vs. basal & 66 & $0.67[0.16-2.55]$ & 0.627 & & & \\
\hline Normal-like vs. basal & 66 & $0.5[0.12-1.81]$ & 0.391 & & & \\
\hline PDL1 group, high vs. Low & 66 & $3.44[1.42-8.63]$ & $2.33 \mathrm{E}-02$ & 66 & $3.49[1.28-10.1]$ & $4.46 \mathrm{E}-02$ \\
\hline $\begin{array}{l}\text { FAC/T response signature, } \\
\text { "pCR-predicted" vs. "no pCR- } \\
\text { predicted" }\end{array}$ & 66 & $3[1.22-7.54]$ & $4.60 \mathrm{E}-02$ & 66 & $1.58[0.53-4.7]$ & 0.487 \\
\hline $\begin{array}{l}\text { Stromal signature, "pCR- } \\
\text { predicted" vs. "no pCR- } \\
\text { predicted" }\end{array}$ & 66 & $2.86[1.18-7.08]$ & 0.052 & 66 & $3.28[1.25-9.17]$ & 0.047 \\
\hline
\end{tabular}

and reproducibility $[55,56]$ and the optimal positivity cutoff is not defined. Second, a positive relationship between protein and mRNA PDL1 expression has been reported in non-IBC [46]. Finally, similar results have been reported in non-IBC at the mRNA level with DNA microarrays and in situ hybridization (ISH) [46].

We found $P D L 1$ overexpression in $38 \%$ of IBC samples. To date, six teams including ours have described PDL1 expression in non-IBC [43-49, 51], with different analytic levels (protein, RNA) and different scoring systems, the rate of expression/overexpression reported ranging between 23 and $55 \%$. In a large series of 5, 454 non-IBC samples, we found $P D L 1$ overexpression in $20 \%$ of cases [50]. Here, with the same analytic method for IBC and non-IBC samples, we observed higher expression in IBC than in non-IBC, and the rate of overexpression was higher in IBC (38\% vs 28\%).

$P D L 1$ expression was heterogeneous in IBC, with a 3-log range of expression levels allowing the search for correlations with other tumor features. "PDL1-high" IBC samples were more frequently ER-negative and more frequently ERBB2-enriched and basal than "PDL1low" samples. These correlations persisted when PDL1 expression was analyzed as continuous value (Wilcoxon's test; data not shown). Similar correlations have been reported in non-IBC in clinical samples and cancer cell lines [44, 45, 49-51]. We did not find any correlation with histological ductal type and high grade, likely because of the relative small series size and the absence of grade 1 samples, but the percent of grade 3 was higher in the "PDL1-high" group ( $82 \%$ vs $70 \%)$, as observed in non-IBC.

The correlations between immune parameters and PDL1 expression as binary variable - and as continuous variable (Wilcoxon's test; data not shown) and the results of our supervised analysis showed that the microenvironment of "PDL1-high" IBC samples is different from that of "PDL1-low" samples and is suggestive of a strong local cytotoxic immune response. "PDL1-high" tumors showed a more dense T-cell infiltration - as already reported by other groups in nonIBC [43, 46, 51] with positive correlation between PDL1 expression and the presence of elevated TILs-, higher expression of T-cell-specific and CD8+ T-cellspecific gene expression signatures, and higher expression of genes coding proteins related to the T-cell receptor. Furthermore, these tumors showed features of T-cell activation. Supervised analysis revealed overexpression of genes coding for T-cells differentiation factors and activation markers, cytotoxic effector molecules (granzymes, perforin, granulyzine), inflammation/anti-tumor cytokines such as interferon, and chemokines related to T-cells activation 

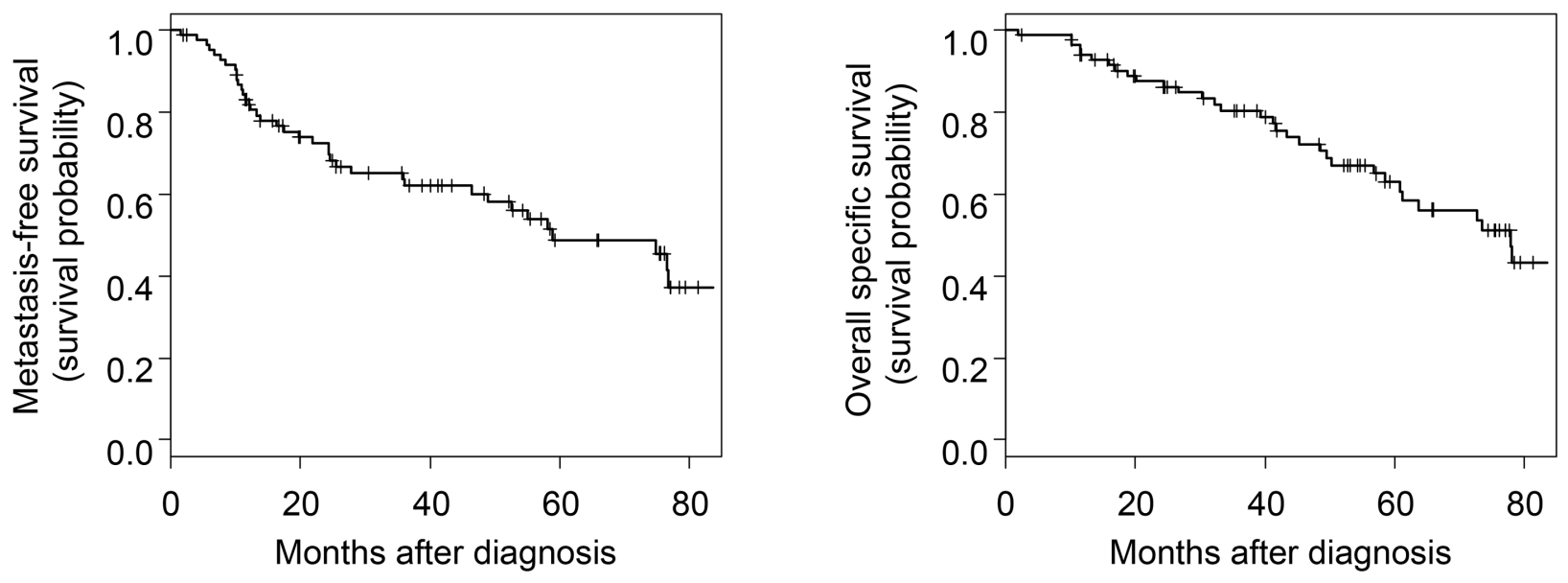

B
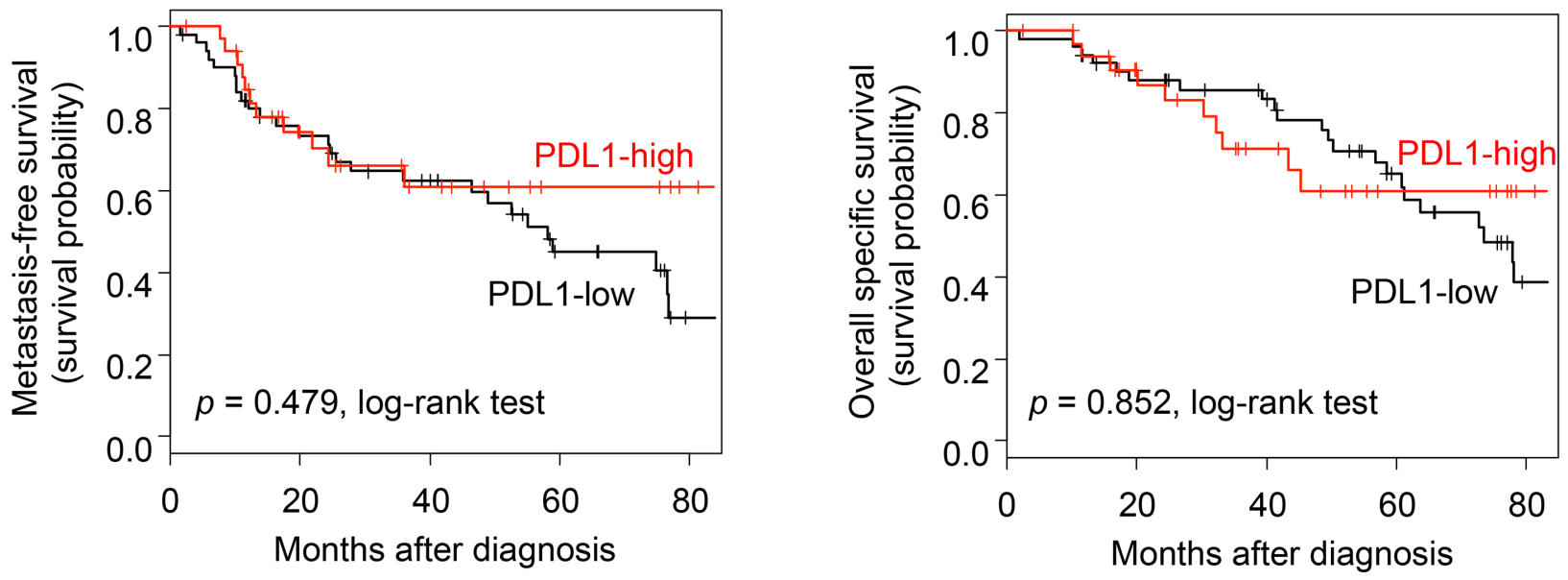

Figure 2: Survival in patients with IBC. A. Kaplan-Meier MFS (left) and OSS (right) curves in the 85 patients with IBC. B. Similar to (A), but according to the PDL1 expression status (red curve: "PDL1-high" group versus black curve: "PDL1-low" group).

and homing. Molecules involved in the processing of endogenous antigens and presentation to immune cells and molecules involved in the degradation of cytosolic peptides were also overexpressed as well as markers of other cells of anti-tumor immunity (e.g. $\gamma \delta$-T-cells, NKG2D+ cells, dendritic-cells, B-cells). Finally, PDL1 expression was associated with two expression signatures (LCK metagene [10] and 28-kinase metagene [11]) reflecting the T-cell cytotoxic immune response, and with a high probability of activation [53] of IFN $\alpha$, IFN $\gamma$, and TNF $\alpha$ pathways. This pro-cytotoxic expression profile of "PDL1-high" samples was suggestive of an activated profile of differentiated T-cells (e.g. EOMES, CD27), $\mathrm{T}_{\mathrm{H}}$ 1-biased (IL12 and IFNinduced pathways), and endowed with cytotoxic effector functions. However, we also noted that some T-cells infiltrating the tumor exhibited the phenotype of exhausted T-cells (CTLA4+/LAG3+/TIM3+/IDO+). T-cells exhaustion can be measured through the loss of secretion of IL2, IFN $\gamma$ and TNF $\alpha$, which occurs in a hierarchical manner. IFN $\gamma$ and TNF $\alpha$ transcripts were still overexpressed in the "PDL1high" group, suggesting that some activated T-cells might be progressively shifting toward a complete exhausted phenotype (still lacking the PD1+CD160+2B4+ markers), most likely as a protective mechanism from the local inflammatory environment and the sustained IFN $\gamma$-mediated response. Reverting this exhausted phenotype through targeting of the surface receptors that inhibit T-cell function, such as PDL1 or LAG3, might considerably improve the local immune response and improve the patients' survival [57]. We hypothesize that PDL1 expression (like the exhausted T-cell phenotype) represents a negative feedback mechanism that follows CD8+ infiltration $[41,58]$. In nonIBC, $P D L 1$ mRNA expression is induced in the tumor microenvironment by activated TILs $[43,46]$ through the release of IFN $\gamma[41,47]$. The correlations that we found between PDL1 expression and the two signatures (LCK 
[10] and 28-kinase [11] metagenes) reflecting the cytotoxic T-cell response, and the activation [53] of IFN $\alpha, \operatorname{IFN} \gamma$, and $\mathrm{TNF} \alpha$ pathways corroborate this hypothesis. Similarly, in a large series of breast cancers, a positive correlation was found between the expression of immunosuppressive checkpoint markers (PD-1, PDL1, CTLA4, and FOXP3) and the expression of proimmune markers, suggestive of a feedback activation of immunosuppressive pathways as part of the immune reaction [16]. Interferon gamma and other inflammatory cytokines, secreted by anti-tumor $\mathrm{T}_{\mathrm{H}} 1$-cells or macrophages, increase PDL1 expression, in response to immune-mediated attack [28], to decrease the cytotoxic local immune response.

These reactive mechanisms may explain the rather counterintuitive correlation between the high expression of PDL1, coding for an immunosuppressive molecule, and a better pathological response to neo-adjuvant chemotherapy. Within the 66 informative patients, the pCR rate was $50 \%$ in the "PDL1-high" group versus $22 \%$ in the "PDL1-low" group, with an OR equal to 3.4. Despite the relative small size of the series, $P D L 1$ expression had independent predictive value in multivariate analysis, when compared to other predictive features, including the classical histo-clinical variables and recent expression signatures identified in non-IBC. The correlation was also significant in uni- and multivariate analyses when PDL1 expression was analyzed as continuous value (Wilcoxon's test; data not shown). Similar results were reported in non-IBC in two series of 265 [50] and 105 [51] samples, respectively. In fact, $P D L 1$ expression represents a surrogate marker of engaged CD8+ TILs, which are known to provide favorable predictive value for response to chemotherapy in non-IBC [59-61] and IBC [62]. Positive correlation of immunosuppressive markers with improved therapeutic response has been reported in other studies as well [9, 16, 63, 64].

Eighty-five stage 3 IBC cases were informative for MFS and OSS, but PDL1 expression was not associated with survival. To date, only three breast cancer studies have studied the prognostic value of PDL1 expression in non-IBC $[46,49,50]$, but results are rather contradictory. In a series of 398 cases studied by ISH assay PDL1 mRNA expression was associated with longer recurrence-free survival [46] but protein expression) was associated with worse overall survival in a different series of 650 cases studied by IHC [49]. More recently, we reported the largest series ever analyzed of non-IBC (1, 080 patients for MFS and 3, 778 for OS) and showed that PDL1 expression was not associated with survival in the whole series of samples, but was associated with better MFS and OS in the basal subtype. Our results in IBC agree with this recent study. Unfortunately, we could not apply prognostic analysis per subtype given the small number of IBC samples.

In conclusion, we show that $P D L 1$ is overexpressed in IBC as compared to non-IBC and that its overexpression as compared to normal breast is observed in $38 \%$ of IBC samples. In IBC, PDL1 overexpression correlates with aggressive molecular subtypes (basal and ERBB2-enriched) and better pathological response to chemotherapy. This first report of $P D L 1$ expression in IBC shows clinical and biological relevance of PDL1 expression in IBC, and independent predictive value for pathological response to chemotherapy in multivariate analysis. Its limitations include: retrospective nature and associated biases such as missing data, size of the series, absence of information for more patients with respect to response to chemotherapy and survival, and use of DNA microarrays that quantify mRNA expression level of both tumor and immune cells. Analysis of larger series, retrospective, then prospective is needed, as well as protein analysis when reliable antibodies are available. If confirmed, PDL1 expression might refine the prediction of pathological response in IBC and improve our ability to better tailor neo-adjuvant therapy. From a therapeutic point of view, because PDL1 expression in could indicate an adaptive mechanism of immune escape [65], the blockade of PDL1 should protect activated T-cells or reactivate inhibited T-cells and increase the antitumor immune response, thus improving the therapeutic response, notably when associated with immunogenic anticancer chemotherapy such as doxorubicin [66, 67]. Given the reported link between PDL1 expression and tumor response to PDL1-inhibitors [25, 26, 28-30], we suggest that IBC patients might be candidates to such new promising therapies. Clinical trials are urgently warranted.

\section{MATERIALS AND METHODS}

\section{Breast cancer samples}

Clinical samples were pre-treatment primary tumor samples from patients with invasive breast adenocarcinoma treated at the Institut Paoli-Calmettes (IPC, Marseille: 71 IBC and 139 non-IBC) and the General Hospital Sint-Augustinus (TCRU, Antwerp: 41 IBC and 55 non-IBC). Each patient gave written informed consent and the study was approved by our institutional review boards. IBC was defined according to the international consensus criteria [1]: rapid onset (less than 6 months) of breast erythema, edema, and/or "peau d'orange", and/or warm breast, with or without an underlying palpable mass. IBC samples were diagnostic biopsies (AJCC stages 3-4) from consecutively treated patients, with available histoclinical annotations and good-quality extracted tumor RNA. Non-IBC samples were surgical specimen in case of early stage disease (AJCC stages 1-2) and diagnostic biopsies in case of advanced stage disease (locally advanced: AJCC stage 3, and metastatic: AJCC stage 4). The final data set contained 306 samples, including 112 IBC samples and 194 non-IBC samples. We also profiled 4 normal breast samples that represented 1 pool of 4 samples from 4 healthy women (reduction mammoplasty), and 3 
commercial pools of respectively 1, 2 and 4 normal breast RNA (Clontech, Palo Alto, CA).

Patients with IBC were treated with neo-adjuvant anthracycline-based chemotherapy often including taxane, and coupled with trastuzumab in more than $40 \%$ of ERBB2positive cases. Chemotherapy was followed by mastectomy and axillary lymph node dissection for clinically nonprogressive and consenting patients, then radiotherapy. The pathological response to chemotherapy was defined on the surgical specimens of both the primary tumor and the lymph nodes using Chevallier grading [68]. From the 112 IBC samples, 66 were available for pCR analysis. After radiotherapy, adjuvant hormone therapy was given to patients with ER-positive IBC, as well as adjuvant trastuzumab in ERBB2-positive cases. A total of 85 patients with nonmetastatic IBC were assessable for survival analysis.

\section{Gene expression data analysis}

Gene expression profiles had been generated in each institution using the same Affymetrix U133 Plus 2.0 human microarrays (Affymetrix ${ }^{\circledR}$, Santa Clara, CA, USA) as previously described [69]. All data were MIAMEcompliant and deposited in the Array-Express database (E-MTAB-1547 and E-MTAB-1006). Data analysis required pre-analytic processing. We first normalized each data set separately using Robust Multichip Average (RMA) [70]. Normalization was done in R using Bioconductor and associated packages. The gene annotation of hybridization probes was updated using NetAffx Annotation files (http:// www.affymetrix.com; release from 01/12/2008). The probes were then mapped based on their EntrezGeneID. When multiple probes mapped to the same GeneID, we retained the one with the highest variance in a particular dataset. We then merged the two data sets by using COMBAT (empirical Bayes) [71] as batch effects removal method, included in the inSilicoMerging R/Bioconductor package [72]. The accuracy of normalization was controlled by principal component analysis (PCA) applied to the 306 tumors and the genes of PAM50 signature [73] (Supplementary Figure 1).

PDL1 (CD274) expression was measured by analyzing the 227458_at Affymetrix probe set whose identity and specificity were verified using the NCBI program BLASTN 2.2.29+ and showed 100\% accuracy. Expression in tumors ( $\mathrm{T}$ ) was measured as discrete value after comparison with mean expression in normal breast samples (NB): overexpression, thereafter designated "PDL1-high" was defined by a T/NB ratio $\geq 2$ and no overexpression ("PDL1-low") by a T/NB ratio $<2$. The cut-off, equal to 2, was arbitrarily chosen, but is frequently used with DNA microarray or qRT-PCR data, based on reproducibility experiments. Correlation analyses were also done with PDL1 expression in continuous values. Thanks to the bimodal distribution of their respective mRNA expression and to avoid biases associated to immunohistochemistry (IHC) analyses across our two institutions, ER, PR, and ERBB2 expressions (negative/ positive) were defined using mRNA expression data of ESR1, PGR, and ERBB2 respectively as described [74]. The molecular subtypes of samples were defined using the PAM50 classifier [73] as previously described [75]. Because of the role of PDL1 in immunity, we also analyzed different immune multigene classifiers that better reflect the functional status of local immune response than assessment of TILs: the LCK metagene [10] and the 28-kinase metagene [11] - two prognostic gene expression signatures published in non-IBC-, three metagenes representing T-cells, CD8+ T-cells and B-cells [52], and three gene expression signatures of immune pathway activity: IFN $\alpha, \operatorname{IFN} \gamma$, and TNF $\alpha$ pathways [53]. Two gene expression signatures predictive for pathological response to neo-adjuvant chemotherapy in non-IBC were also applied: the FAC/T response signature [76] and the stromal signature [77].

Finally, to explore the biological pathways associated with PDL1 expression in IBC, we applied supervised analysis to the 112 samples and the 14,338 genes remaining after filtering (removal of probes with low and poorly measured expression and standard deviation inferior to $0.25 \log _{2}$ units) for comparing the gene expression profiles between the "PDL1-high" versus "PDL1-low" tumors. We used Significant Analysis of Microarrays (SAM) [78] algorithm and considered $p$-values, corrected for multiple comparisons (false discovery rate; FDR), as significant when smaller than 0.05 . Ontology analysis of the resulting gene list was based on the GO biological processes of the Database for Annotation, Visualisation and Integrated Discovery (DAVID; http://david.abcc.ncifcrf.gov/).

\section{Statistical analysis}

Correlations between PDL1 expression and histoclinical factors were calculated with the Student's $t$-test for expression assessed as continuous variable and the Fisher's exact test for expression assessed as binary variable (PDL1-high and PDL1-low). The pathological complete response (pCR) to neo-adjuvant chemotherapy was defined as the absence of invasive cancer in both breast and axillary lymph nodes (Chevallier grades 1 and 2), whereas Chevallier grades 3 and 4 were considered as no-pCR. MFS was calculated from the date of diagnosis until the date of first distant relapse. OSS was calculated from the date of diagnosis until the date of IBC-related death. Follow-up was measured from the date of diagnosis to the date of last news for event-free patients. Survivals were calculated using the Kaplan-Meier method and curves were compared with the log-rank test. Univariate and multivariate survival analyses were done using a logistic regression analysis for $\mathrm{pCR}$ analysis (glm function and significance estimated by specifying a binomial family for model with a logit link) and Cox regression analysis for survival analysis (Wald test). Variables tested in univariate 
analyses included patients' age at time of diagnosis $(\leq 50$ years $v s>50$ ), histological type (ductal $v s$ other) and grade (3 vs 2; no grade 1 in our IBC series), ER, PR and ERBB2 status (positive $v s$ negative), molecular subtypes, and PDL1 expression status ("PDL1-high" vs "PDL1low"). Variables with a $p$-value $<0.10$ in univariate analysis were tested in multivariate analysis. All statistical tests were two-sided at the 5\% level of significance. Statistical analysis was done using the survival package (version 2.30) in the $\mathrm{R}$ software (version 2.9.1; http:// www.cran.r-project.org/). We followed the reporting REcommendations for tumor MARKer prognostic studies (REMARK criteria) [79].

\section{ACKNOWLEDGMENTS}

Our work is supported by the Institut National du Cancer (INCa) Translational Research Grant 2007 (FB), Translational Research Grant 2009 (DB) and Biologic Research Grant 2010 «IVOIRES »(FB), the Ligue Nationale Contre le Cancer (label DB) and SIRIC (INCaDGOS-Inserm 6038 grant).

\section{CONFLICTS OF INTEREST}

The authors have no conflict of interest to declare.

\section{REFERENCES}

1. Dawood S, Merajver SD, Viens P, Vermeulen PB, Swain SM, Buchholz TA, Dirix LY, Levine PH, Lucci A, Krishnamurthy S, Robertson FM, Woodward WA, Yang WT, et al. International expert panel on inflammatory breast cancer: consensus statement for standardized diagnosis and treatment. Ann Oncol. 2011; 22:515-523.

2. Robertson FM, Bondy M, Yang W, Yamauchi H, Wiggins S, Kamrudin S, Krishnamurthy S, Le-Petross H, Bidaut L, Player AN, Barsky SH, Woodward WA, Buchholz T, et al. Inflammatory breast cancer: the disease, the biology, the treatment. CA Cancer J Clin. 2010; 60:351-375.

3. Monneur A, Bertucci F, Viens P, Goncalves A. Systemic treatments of inflammatory breast cancer: an overview. Bull Cancer. 2014; 101:1080-1088.

4. Viens P, Tarpin C, Roche H, Bertucci F. Systemic therapy of inflammatory breast cancer from high-dose chemotherapy to targeted therapies: the French experience. Cancer. 2010; 116:2829-2836.

5. Charafe-Jauffret E, Tarpin C, Viens P, Bertucci F. Defining the molecular biology of inflammatory breast cancer. Semin Oncol. 2008; 35:41-50.

6. Ventura AC, Merajver SD. Genetic determinants of aggressive breast cancer. Annu Rev Med. 2008; 59:199-212.

7. Bertucci F, Finetti P, Vermeulen P, Van Dam P, Dirix L, Birnbaum D, Viens P, Van Laere S. Genomic profiling of inflammatory breast cancer: a review. Breast. 2014; 23:538-545.

8. Ali HR, Provenzano E, Dawson SJ, Blows FM, Liu B, Shah M, Earl HM, Poole CJ, Hiller L, Dunn JA, Bowden SJ, Twelves C, Bartlett JM, et al. Association between CD8+ T-cell infiltration and breast cancer survival in 12, 439 patients. Ann Oncol. 2014; 25:1536-1543.

9. Loi S, Michiels S, Salgado R, Sirtaine N, Jose V, Fumagalli D, Kellokumpu-Lehtinen PL, Bono P, Kataja V, Desmedt C, Piccart MJ, Loibl S, Denkert C, et al. Tumor infiltrating lymphocytes are prognostic in triple negative breast cancer and predictive for trastuzumab benefit in early breast cancer: results from the FinHER trial. Ann Oncol. 2014; 25:1544-1550.

10. Rody A, Holtrich U, Pusztai L, Liedtke C, Gaetje R, Ruckhaeberle E, Solbach C, Hanker L, Ahr A, Metzler D, Engels K, Karn T, Kaufmann M. T-cell metagene predicts a favorable prognosis in estrogen receptor-negative and HER2-positive breast cancers. Breast Cancer Res. 2009; 11:R15.

11. Sabatier R, Finetti P, Mamessier E, Raynaud S, Cervera N, Lambaudie E, Jacquemier J, Viens P, Birnbaum D, Bertucci F. Kinome expression profiling and prognosis of basal breast cancers. Mol Cancer. 2011; 10:86.

12. Teschendorff AE, Miremadi A, Pinder SE, Ellis IO, Caldas C. An immune response gene expression module identifies a good prognosis subtype in estrogen receptor negative breast cancer. Genome Biol. 2007; 8:R157.

13. Bianchini G, Qi Y, Alvarez RH, Iwamoto T, Coutant C, Ibrahim NK, Valero V, Cristofanilli M, Green MC, Radvanyi L, Hatzis C, Hortobagyi GN, Andre F, et al. Molecular anatomy of breast cancer stroma and its prognostic value in estrogen receptor-positive and -negative cancers. J Clin Oncol. 2010; 28:4316-4323.

14. Sabatier R, Finetti P, Cervera N, Lambaudie E, Esterni B, Mamessier E, Tallet A, Chabannon C, Extra JM, Jacquemier J, Viens P, Birnbaum D, Bertucci F. A gene expression signature identifies two prognostic subgroups of basal breast cancer. Breast Cancer Res Treat. 2011; 126:407-420.

15. Denkert C, Loibl S, Noske A, Roller M, Muller BM, Komor M, Budczies J, Darb-Esfahani S, Kronenwett R, Hanusch C, von Torne C, Weichert W, Engels K, et al. Tumor-associated lymphocytes as an independent predictor of response to neoadjuvant chemotherapy in breast cancer. J Clin Oncol. 2010; 28:105-113.

16. Denkert C, von Minckwitz G, Brase JC, Sinn BV, Gade S, Kronenwett R, Pfitzner BM, Salat C, Loi S, Schmitt WD, Schem C, Fisch K, Darb-Esfahani S, et al. Tumorinfiltrating lymphocytes and response to neoadjuvant chemotherapy with or without Carboplatin in human epidermal growth factor receptor 2-positive and triple-negative primary breast cancers. J Clin Oncol. 2015; 33:983-991.

17. Salgado R, Denkert C, Demaria S, Sirtaine N, Klauschen F, Pruneri G, Wienert S, Van den Eynden G, Baehner FL, 
Penault-Llorca F, Perez EA, Thompson EA, Symmans WF, et al. The evaluation of tumor-infiltrating lymphocytes (TILs) in breast cancer: recommendations by an International TILs Working Group 2014. Ann Oncol. 2015; 26:259-271.

18. Ahmadzadeh M, Johnson LA, Heemskerk B, Wunderlich JR, Dudley ME, White DE, Rosenberg SA. Tumor antigen-specific CD8 T cells infiltrating the tumor express high levels of PD-1 and are functionally impaired. Blood. 2009; 114:1537-1544.

19. Dong H, Strome SE, Salomao DR, Tamura H, Hirano F, Flies DB, Roche PC, Lu J, Zhu G, Tamada K, Lennon VA, Celis E, Chen L. Tumor-associated B7-H1 promotes T-cell apoptosis: a potential mechanism of immune evasion. Nat Med. 2002; 8:793-800.

20. Francisco LM, Salinas VH, Brown KE, Vanguri VK, Freeman GJ, Kuchroo VK, Sharpe AH. PD-L1 regulates the development, maintenance, and function of induced regulatory T cells. J Exp Med. 2009; 206:3015-3029.

21. Hamel KM, Cao Y, Wang Y, Rodeghero R, Kobezda T, Chen L, Finnegan A. B7-H1 expression on non-B and non- $\mathrm{T}$ cells promotes distinct effects on $\mathrm{T}$ - and B-cell responses in autoimmune arthritis. Eur J Immunol. 2010; 40:3117-3127.

22. Zou W, Chen L. Inhibitory B7-family molecules in the tumour microenvironment. Nat Rev Immunol. 2008; 8:467-477.

23. Iwai $\mathrm{Y}$, Ishida $\mathrm{M}$, Tanaka $\mathrm{Y}$, Okazaki $\mathrm{T}$, Honjo $\mathrm{T}$, Minato N. Involvement of PD-L1 on tumor cells in the escape from host immune system and tumor immunotherapy by PD-L1 blockade. Proc Natl Acad Sci U S A. 2002; 99:12293-12297.

24. Reiss KA, Forde PM, Brahmer JR. Harnessing the power of the immune system via blockade of PD-1 and PD-L1: a promising new anticancer strategy. Immunotherapy. 2014; 6:459-475.

25. Brahmer JR, Tykodi SS, Chow LQ, Hwu WJ, Topalian SL, Hwu P, Drake CG, Camacho LH, Kauh J, Odunsi K, Pitot HC, Hamid O, Bhatia S, et al. Safety and activity of anti-PD-L1 antibody in patients with advanced cancer. N Engl J Med. 2012; 366:2455-2465.

26. Topalian SL, Hodi FS, Brahmer JR, Gettinger SN, Smith DC, McDermott DF, Powderly JD, Carvajal RD, Sosman JA, Atkins MB, Leming PD, Spigel DR, Antonia SJ, et al. Safety, activity, and immune correlates of anti-PD-1 antibody in cancer. N Engl J Med. 2012; 366:2443-2454.

27. Powles T, Eder JP, Fine GD, Braiteh FS, Loriot Y, Cruz C, Bellmunt J, Burris HA, Petrylak DP, Teng SL, Shen X, Boyd Z, Hegde PS, et al. MPDL3280A (anti-PD-L1) treatment leads to clinical activity in metastatic bladder cancer. Nature. 2014; 515:558-562.

28. Taube JM, Klein A, Brahmer JR, Xu H, Pan X, Kim JH, Chen L, Pardoll DM, Topalian SL, Anders RA. Association of PD-1, PD-1 Ligands, and Other Features of the Tumor Immune Microenvironment with Response to Anti-PD-1 Therapy. Clin Cancer Res. 2014; 20:5064-5074.
29. Herbst RS, Soria JC, Kowanetz M, Fine GD, Hamid O, Gordon MS, Sosman JA, McDermott DF, Powderly JD, Gettinger SN, Kohrt HE, Horn L, Lawrence DP, et al. Predictive correlates of response to the anti-PD-L1 antibody MPDL3280A in cancer patients. Nature. 2014; 515:563-567.

30. Tumeh PC, Harview CL, Yearley JH, Shintaku IP, Taylor EJ, Robert L, Chmielowski B, Spasic M, Henry G, Ciobanu V, West AN, Carmona M, Kivork C, et al. PD-1 blockade induces responses by inhibiting adaptive immune resistance. Nature. 2014; 515:568-571.

31. Konishi J, Yamazaki K, Azuma M, Kinoshita I, DosakaAkita H, Nishimura M. B7-H1 expression on non-small cell lung cancer cells and its relationship with tumor-infiltrating lymphocytes and their PD-1 expression. Clin Cancer Res. : 2004; 10:5094-5100.

32. Nomi $\mathrm{T}$, Sho $\mathrm{M}$, Akahori $\mathrm{T}$, Hamada $\mathrm{K}$, Kubo A, Kanehiro H, Nakamura S, Enomoto K, Yagita H, Azuma M, Nakajima Y. Clinical significance and therapeutic potential of the programmed death-1 ligand/programmed death-1 pathway in human pancreatic cancer. Clin Cancer Res. 2007; 13:2151-2157.

33. Ohigashi Y, Sho M, Yamada Y, Tsurui Y, Hamada K, Ikeda N, Mizuno T, Yoriki R, Kashizuka H, Yane K, Tsushima F, Otsuki N, Yagita H, et al. Clinical significance of programmed death-1 ligand-1 and programmed death-1 ligand-2 expression in human esophageal cancer. Clin Cancer Res. 2005; 11:2947-2953.

34. Strome SE, Dong H, Tamura H, Voss SG, Flies DB, Tamada K, Salomao D, Cheville J, Hirano F, Lin W, Kasperbauer JL, Ballman KV, Chen L. B7-H1 blockade augments adoptive T-cell immunotherapy for squamous cell carcinoma. Cancer Res. 2003; 63:6501-6505.

35. Thompson RH, Dong H, Lohse CM, Leibovich BC, Blute ML, Cheville JC, Kwon ED. PD-1 is expressed by tumor-infiltrating immune cells and is associated with poor outcome for patients with renal cell carcinoma. Clin Cancer Res. 2007; 13:1757-1761.

36. Thompson RH, Gillett MD, Cheville JC, Lohse CM, Dong H, Webster WS, Krejci KG, Lobo JR, Sengupta S, Chen L, Zincke H, Blute ML, Strome SE, et al. Costimulatory B7-H1 in renal cell carcinoma patients: Indicator of tumor aggressiveness and potential therapeutic target. Proc Natl Acad Sci U S A. 2004; 101:17174-17179.

37. Hamanishi J, Mandai M, Iwasaki M, Okazaki T, Tanaka Y, Yamaguchi K, Higuchi T, Yagi H, Takakura K, Minato N, Honjo T, Fujii S. Programmed cell death 1 ligand 1 and tumor-infiltrating CD8+ T lymphocytes are prognostic factors of human ovarian cancer. Proc Natl Acad Sci U S A. 2007; 104:3360-3365.

38. Wintterle S, Schreiner B, Mitsdoerffer M, Schneider D, Chen L, Meyermann R, Weller M, Wiendl H. Expression of the B7-related molecule B7-H1 by glioma cells: a potential mechanism of immune paralysis. Cancer Res. 2003; 63:7462-7467. 
39. Badoual C, Hans S, Merillon N, Van Ryswick C, Ravel P, Benhamouda N, Levionnois E, Nizard M, Si-Mohamed A, Besnier N, Gey A, Rotem-Yehudar R, Pere H, et al. PD-1expressing tumor-infiltrating $\mathrm{T}$ cells are a favorable prognostic biomarker in HPV-associated head and neck cancer. Cancer Res. 2013; 73:128-138.

40. Droeser RA, Hirt C, Viehl CT, Frey DM, Nebiker C, Huber X, Zlobec I, Eppenberger-Castori S, Tzankov A, Rosso R, Zuber M, Muraro MG, Amicarella F, et al. Clinical impact of programmed cell death ligand 1 expression in colorectal cancer. Eur J Cancer. 2013; 49:2233-2242.

41. Spranger S, Spaapen RM, Zha Y, Williams J, Meng Y, Ha TT, Gajewski TF. Up-regulation of PD-L1, IDO, and $\mathrm{T}$ (regs) in the melanoma tumor microenvironment is driven by CD8(+) T cells. Sci Transl Med. 2013; 5:200ra116.

42. Bertucci F, Finetti P, Mamessier E, Pantaleo MA, Astolfi A, Ostrowski J, Birnbaum D. PDL1 expression is an independent prognostic factor in localized GIST. Oncoimmunology. 2015. in press.

43. Ghebeh H, Barhoush E, Tulbah A, Elkum N, Al-Tweigeri T, Dermime S. FOXP3+ Tregs and B7-H1+/PD-1+ T lymphocytes co-infiltrate the tumor tissues of high-risk breast cancer patients: Implication for immunotherapy. BMC Cancer. 2008; 8:57.

44. Ghebeh H, Mohammed S, Al-Omair A, Qattan A, Lehe C, Al-Qudaihi G, Elkum N, Alshabanah M, Bin Amer S, Tulbah A, Ajarim D, Al-Tweigeri T, Dermime S. The B7-H1 (PD-L1) T lymphocyte-inhibitory molecule is expressed in breast cancer patients with infiltrating ductal carcinoma: correlation with important high-risk prognostic factors. Neoplasia. 2006; 8:190-198.

45. Ghebeh H, Tulbah A, Mohammed S, Elkum N, Bin Amer SM, Al-Tweigeri T, Dermime S. Expression of $\mathrm{B} 7-\mathrm{H} 1$ in breast cancer patients is strongly associated with high proliferative $\mathrm{Ki}-67$-expressing tumor cells. Int J Cancer. 2007; 121:751-758.

46. Schalper KA, Velcheti V, Carvajal D, Wimberly H, Brown J, Pusztai L, Rimm DL. In situ tumor PD-L1 mRNA expression is associated with increased TILs and better outcome in breast carcinomas. Clin Cancer Res. 2014; 20:2773-2782.

47. Soliman H, Khalil F, Antonia S. PD-L1 expression is increased in a subset of basal type breast cancer cells. PLoS One. 2014; 9:e88557.

48. Mittendorf EA, Philips AV, Meric-Bernstam F, Qiao N, Wu Y, Harrington S, Su X, Wang Y, Gonzalez-Angulo AM, Akcakanat A, Chawla A, Curran M, Hwu P, et al. PD-L1 expression in triple-negative breast cancer. Cancer immunology research. 2014; 2:361-370.

49. Muenst S, Schaerli AR, Gao F, Daster S, Trella E, Droeser RA, Muraro MG, Zajac P, Zanetti R, Gillanders WE, Weber WP, Soysal SD. Expression of programmed death ligand 1 (PD-L1) is associated with poor prognosis in human breast cancer. Breast Cancer Res Treat. 2014; 146:15-24.
50. Sabatier R, Finetti P, Mamessier E, Adélaïde J, Chaffanet M, Ali HR, Viens P, Caldas C, Birnbaum D, Bertucci F. Prognostic and predictive value of PDL1 expression in breast cancer. OncoTarget. 2015; 6:5449-5464.

51. Wimberly H, Brown JR, Schalper KA, Haack H, Silver MR, Nixon C, Bossuyt V, Pusztai L, Lannin DR, Rimm DL. PDL1 expression correlates with tumor-infiltrating lymphocytes and response to neoadjuvant chemotherapy in breast cancer. Cancer Immunol Res. 2015; 3:326-332.

52. Palmer C, Diehn M, Alizadeh AA, Brown PO. Cell-type specific gene expression profiles of leukocytes in human peripheral blood. BMC Genomics. 2006; 7:115.

53. Gatza ML, Lucas JE, Barry WT, Kim JW, Wang Q, Crawford MD, Datto MB, Kelley M, Mathey-Prevot B, Potti A, Nevins JR. A pathway-based classification of human breast cancer. Proc Natl Acad Sci U S A. 2010; 107:6994-6999.

54. Velcheti V, Schalper KA, Carvajal DE, Anagnostou VK, Syrigos KN, Sznol M, Herbst RS, Gettinger SN, Chen L, Rimm DL. Programmed death ligand-1 expression in nonsmall cell lung cancer. Lab Invest. 2014; 94:107-116.

55. Gadiot J, Hooijkaas AI, Kaiser AD, van Tinteren H, van Boven H, Blank C. Overall survival and PD-L1 expression in metastasized malignant melanoma. Cancer. 2011; 117:2192-2201.

56. Rimm D, Schalper K, Pusztai L. Unvalidated antibodies and misleading results. Breast Cancer Res Treat. 2014; 147:457-458.

57. Nguyen LT, Ohashi PS. Clinical blockade of PD1 and LAG3 - potential mechanisms of action. Nat Rev Immunol. 2014; $15: 45-56$.

58. Karasar P, Esendagli G. T helper responses are maintained by basal-like breast cancer cells and confer to immune modulation via upregulation of PD-1 ligands. Breast Cancer Res Treat. 2014; 145:605-614.

59. Loi S, Sirtaine N, Piette F, Salgado R, Viale G, Van Eenoo F, Rouas G, Francis P, Crown JP, Hitre E, de Azambuja E, Quinaux E, Di Leo A, et al. Prognostic and predictive value of tumor-infiltrating lymphocytes in a phase III randomized adjuvant breast cancer trial in nodepositive breast cancer comparing the addition of docetaxel to doxorubicin with doxorubicin-based chemotherapy: BIG 02-98. J Clin Oncol. 2013; 31:860-867.

60. Ono M, Tsuda H, Shimizu C, Yamamoto S, Shibata T, Yamamoto H, Hirata T, Yonemori K, Ando M, Tamura K, Katsumata N, Kinoshita T, Takiguchi Y, et al. Tumorinfiltrating lymphocytes are correlated with response to neoadjuvant chemotherapy in triple-negative breast cancer. Breast Cancer Res Treat. 2012; 132:793-805.

61. West NR, Milne K, Truong PT, Macpherson N, Nelson BH, Watson PH. Tumor-infiltrating lymphocytes predict response to anthracycline-based chemotherapy in estrogen receptor-negative breast cancer. Breast Cancer Res. 2011; 13:R126. 
62. Bertucci F, Ueno NT, Finetti P, Vermeulen P, Lucci A, Robertson FM, Marsan M, Iwamoto T, Krishnamurthy S, Masuda H, Van Dam P, Woodward WA, Cristofanilli M, et al. Gene expression profiles of inflammatory breast cancer: correlation with response to neoadjuvant chemotherapy and metastasis-free survival. Ann Oncol. 2014; 25:358-365.

63. Jacquemier J, Bertucci F, Finetti P, Esterni B, CharafeJauffret E, Thibult ML, Houvenaeghel G, Van den Eynde B, Birnbaum D, Olive D, Xerri L. High expression of indoleamine 2, 3-dioxygenase in the tumour is associated with medullary features and favourable outcome in basal-like breast carcinoma. Int J Cancer. 2012; 130:96-104.

64. West NR, Kost SE, Martin SD, Milne K, Deleeuw RJ, Nelson BH, Watson PH. Tumour-infiltrating FOXP3(+) lymphocytes are associated with cytotoxic immune responses and good clinical outcome in oestrogen receptornegative breast cancer. Br J Cancer. 2013; 108:155-162.

65. Taube JM, Anders RA, Young GD, Xu H, Sharma R, McMiller TL, Chen S, Klein AP, Pardoll DM, Topalian SL, Chen L. Colocalization of inflammatory response with B7-h1 expression in human melanocytic lesions supports an adaptive resistance mechanism of immune escape. Sci Transl Med. 2012; 4:127ra137.

66. Ramakrishnan R, Gabrilovich DI. Mechanism of synergistic effect of chemotherapy and immunotherapy of cancer. Cancer Immunol Immunoth. 2011; 60:419-423.

67. Vacchelli E, Senovilla L, Eggermont A, Fridman WH, Galon J, Zitvogel L, Kroemer G, Galluzzi L. Trial watch: Chemotherapy with immunogenic cell death inducers. Oncoimmunology. 2013; 2:e23510.

68. Chevallier B, Chollet P, Merrouche Y, Roche H, Fumoleau P, Kerbrat P, Genot JY, Fargeot P, Olivier JP, Fizames $\mathrm{C}$ and et al, et al. Lenograstim prevents morbidity from intensive induction chemotherapy in the treatment of inflammatory breast cancer. J Clin Oncol. 1995; 13:1564-1571.

69. Bertucci F, Finetti P, Cervera N, Charafe-Jauffret E, Mamessier E, Adelaide J, Debono S, Houvenaeghel G, Maraninchi D, Viens P, Charpin C, Jacquemier J, Birnbaum D. Gene expression profiling shows medullary breast cancer is a subgroup of basal breast cancers. Cancer Res. 2006; 66:4636-4644.

70. Irizarry RA, Hobbs B, Collin F, Beazer-Barclay YD, Antonellis KJ, Scherf U, Speed TP. Exploration, normalization, and summaries of high density oligonucleotide array probe level data. Biostatistics. 2003; 4:249-264.

71. Johnson WE, Li C, Rabinovic A. Adjusting batch effects in microarray expression data using empirical Bayes methods. Biostatistics. 2007; 8:118-127.

72. Taminau J, Steenhoff D, Coletta A, Meganck S, Lazar C, de Schaetzen V, Duque R, Molter C, Bersini H, Nowe A, Weiss Solis DY. inSilicoDb: an R/Bioconductor package for accessing human Affymetrix expert-curated datasets from GEO. Bioinformatics. 2011; 27:3204-3205.

73. Parker JS, Mullins M, Cheang MC, Leung S, Voduc D, Vickery T, Davies S, Fauron C, He X, Hu Z, Quackenbush JF, Stijleman IJ, Palazzo J, et al. Supervised risk predictor of breast cancer based on intrinsic subtypes. J Clin Oncol. 2009; 27:1160-1167.

74. Lehmann BD, Bauer JA, Chen X, Sanders ME, Chakravarthy AB, Shyr Y, Pietenpol JA. Identification of human triple-negative breast cancer subtypes and preclinical models for selection of targeted therapies. J Clin Invest. 2011; 121:2750-2767.

75. Finetti P, Cervera N, Charafe-Jauffret E, Chabannon C, Charpin C, Chaffanet M, Jacquemier J, Viens P, Birnbaum D, Bertucci F. Sixteen-kinase gene expression identifies luminal breast cancers with poor prognosis. Cancer Res. 2008; 68:767-776.

76. Hess KR, Anderson K, Symmans WF, Valero V, Ibrahim N, Mejia JA, Booser D, Theriault RL, Buzdar AU, Dempsey PJ, Rouzier R, Sneige N, Ross JS, et al. Pharmacogenomic predictor of sensitivity to preoperative chemotherapy with paclitaxel and fluorouracil, doxorubicin, and cyclophosphamide in breast cancer. J Clin Oncol. 2006; 24:4236-4244.

77. Farmer P, Bonnefoi H, Anderle P, Cameron D, Wirapati P, Becette V, Andre S, Piccart M, Campone M, Brain E, Macgrogan G, Petit T, Jassem J, et al. A stroma-related gene signature predicts resistance to neoadjuvant chemotherapy in breast cancer. Nat Med. 2009; 15:68-74.

78. Tusher VG, Tibshirani R, Chu G. Significance analysis of microarrays applied to the ionizing radiation response. Proc Natl Acad Sci U S A. 2001; 98:5116-5121.

79. McShane LM, Altman DG, Sauerbrei W, Taube SE, Gion M, Clark GM and Statistics Subcommittee of the NCIEWGoCD. REporting recommendations for tumour MARKer prognostic studies (REMARK). Br J Cancer. 2005; 93:387-391. 